\title{
Effect of Guidelines Protocol for Nurses' Performance Regarding Care Provided toward Poisoned Pre-school Age Children
}

\author{
Noura Abd El fatah Mahmoud ${ }^{1}$, Amal Mohamed El-Dakhankhny ${ }^{2}$, Basma Rabea Abdel- \\ Sadik $^{3}$ and Amal Abd El Aziz Abdel-Salam ${ }^{4}$ \\ (1) M. Sc Pediatric Nursing - faculty of Nursing-Benha , (2) Professor of Pediatric Nursing - \\ Faculty of Nursing- El Zigzag University, (3) Professor of Pediatric Nursing - Faculty of Nursing- \\ Benha University and (4) Assistance Professor of Pediatric Nursing - Faculty of Nursing-Benha \\ University
}

\begin{abstract}
Background: Nurses play a crucial role at poisoned center unites, as they are responsible for administering nursing care to poisoned children. Aim of the study was to identify effect of guideline protocol for nurses' performance regarding care provided toward poisoned pre- school age children. Design: A quesi experimental research design was utilized in the current study. Setting: The current study was conducted at Benha poisoning center in University Hospital at Benha city. Sample: All nurses work in poison center 50 nurses was participated in the current study. Tools of data collection (I): A structured interviewing questionnaire consisted of three parts, part (1): personal data for nurses, part (2): personal data for pre- school age and part (3): nurses' knowledge regarding poisoned children and Tool (II): An observational checklist of selected nursing procedures to evaluate the practice of the nurses regarding poisoned children. Results: More than two third of studied nurses had poor level of total knowledge scores and the most of them had incompetent in their total performance scores also, there was a positive correlation between total knowledge and practice score regarding nursing care procedure in pre and post guideline. There was no statically significant relation between of the studied nurses' total knowledge scores and their personal characteristics, there was no statically significant relation between of the studied nurses' total performance scores and their personal characteristics. Conclusion: There was a highly statically significant improvement in the studied nurses' knowledge and practice score regarding poisoned preschool age guideline protocol intervention when compared with pre guideline protocol intervention. Recommendations: Adding poisoning course nursing curriculum.
\end{abstract}

Key words: guideline protocol, poisoned center poisoning, pre-school age, children, nurses' performance

\section{Introduction}

A poison is a substance which introduced into the body and destroys the tissues and enzymes. It can cause a serious threat to life, depending on the amount, type and concentration of the poisonous substance. So the immediate nursing intervention is very important. Poisoning is a relatively common medical emergency worldwide and raises particular problems of diagnosis and treatment especially in children, regardless of the path of the toxic enters the body (ingestion, inhalation, injection, or skin absorption) (Saikia et al., 2020). 


\section{Effect of Guidelines Protocol for Nurses' Performance Regarding Care Provided toward Poisoned Pre-school Age Children}

Poisoning is the exposure of an individual to a substance that can cause symptoms and signs of organ dysfunction leading to injury or death children less than 6 years of age and having male preponderance as they are more active with a drive to explore the environment. Poisoning by accidental or deliberate ingestion, injection, or inhalation of medicinal and chemicals poisons are common medical emergencies. Deaths due to unintentional poisoning are more common in low and middle income group of countries (Hassan \& Mohmed, 2020).

Preschool children want to touch, taste, smell, hear, and test things for themselves and they are eager to learn. Children learn by experiencing and by doing. Preschoolers learn from their play. They are busy developing skills, using language, and struggling to gain inner control. Preschoolers want to establish themselves as separate from their parents. They are more independent than toddlers. They can express their needs since they have greater command of language (Shalaby et al., 2015).

The most common types of poisoning are medication, corrosive and petroleum. Also, Children come to hospital when they have signs and symptoms of poisoning like gastrointestinal sign (anorexia, nausea, vomiting, abdominal colic, diarrhea and constipation) and neurological signs: dizziness, anxiety, delirium, confusion, headache, convulsion, slurred, speech and coma) (Vilaca et al., 2019).

Emergency nurses play important roles in their care and management of children with acute poisoning that consists of four elements: initial life support, decontamination, in some cases antidotal therapy and enhanced elimination. The initial life support consists of airway management and correction of circulatory status. Protecting the airway is essential in order to prevent aspiration and respiratory insufficiency due to lowered consciousness. Arrhythmias and hemodynamic compromises are corrected and managed as would be the case with any patient in critical compromises are corrected and managed as would be the case with any child in critical cases (Nixon et al., 2014).

\section{Significance of the study}

In Benha University hospital, the total number of children who are admitted due to poisoning is 4653 child in the period of 2018;2019 and 2164 in 2020 according to Benha statistics. Poisoning is also the third most common emergencies of pediatrics leading to high social and economic burden. The high prevalence of acute poisoning in children is attributed to the curiosity of children especially those aged less than 5 years because they taste or swallow harmful substances. Acute poisoning has become a significant health problem worldwide particularly in developing countries.

\section{Aim of study:}

The present study aimed to evaluate the effect of guideline protocol for nurses' performance regarding care provided toward poisoned preschool age children.

\section{Research Hypothesis}

The guideline protocol will improve nurses' knowledge and practice about care provided toward poisoned preschool age children.

\section{Subject and Methods: \\ Research design}

A quasi- experimental research design was utilized to conduct study.

\section{Setting}

The current study was conducted at at Benha Poisoning Center in University hospital at Benha city. 


\section{Sample}

Sample (I): A convenience sample of all available nurses $(n=50)$ working at the previously mentioned setting regardless of their characteristics and caring for the poisoned pre-school children.

Sample (II): Purposive sample $(\mathrm{n}=100)$ poisoned pre-school children admitted poisoned center

\section{Tools of data collection (pre | post guideline} protocol)

Data were collected through using the following tools:

Tool (1): A structured interviewing questionnaire sheet:

This tool was designed by the researcher in the light of reviewing relevant articles, previous studies and researches. It was written in Arabic language and composed three parts:

\section{The first part:}

This part was of concerned with personal characteristics for the studied nurses which included gender, age, years of experiences and attending of training program about poisoning

\section{The second part:}

This part was concerned with firstly; personal characteristics of studied children which included age, gender, child rank

Secondly; Medical characteristics of studied children which included type of poisoning, route of poisoning, signs and symptoms(pre and post format).

\section{The third part:}

Nurses' knowledge regarding poisoned preschool age (pre and post test formate)

This part was developed by the researcher to evaluate the nurses' knowledge regarding selected children nursing procedures in the clinical experiences. It consisted of 41 questions about definition, and types, routes, forms, signs and symptoms of poisoning.

\section{Scoring system for knowledge:}

All knowledge items were checked with a model key answer, where the complete response was scored 2 degrees, incomplete response was scored 1 degree and 0 for don't know. Total scoring system was

$$
\begin{array}{ll}
\text { - } & \text { Poor }=<60 \% \\
\text { - } & \text { Average }=60 \% \\
\text { - } \quad \text { Good }=80 \%-100 \%
\end{array}
$$

Tool (II): Observational Checklists for Selected Pediatric Nursing Procedures)

This checklist was adapted from (Anant et al., (2018), Nickson, (2017), Shief et al., (2017) and Alazab et al., ( 2015) and modified it to assess practices related to care of poisoned preschool age. The checklists were used to evaluate nurses' practices regarding selected nursing procedures (10 procedures), which included;

- Immediate nursing care provided to poisoned children at admission (15 steps)

- Nursing assessment vital signs and clinical examination consist of (12 steps)

- Procedure of cardiopulmonary resuscitation (CPR) It consisted of (3) parts firstly( nurse role before CPR contain (10) steps), secondly during CPR (10) steps) and third after (3) steps)

- Procedure of mouth care consist of (9) steps, pain assessment scale consist of (1) steps, skin care procedure consisted of (10) steps

- Procedure of gastric lavage. It consisted of 3 parts firstly (nurse role before gastric lavage (6) steps, secondly during gastric lavage (13) steps thirdly and after (4) steps)

- Electrical cardio graph procedure (ECG) consisted of (13) steps

- Glasgow coma scale. It consisted of (3) steps

Alert verbal painful unresponsiveness (AVPU) scales (conscious level). It consisted of (1) steps. 


\section{Scoring system of observational checklists for selected pediatric nursing procedures:}

The score of each item of the previous tool was ranged as the following: Done correctly scored $=$ consisted $=(1)$ degree and not done $=(0)$ when completely and correctly done and grade (0) if not done for steps of each procedure. Total scored of all procedure was converted into percent scores and divided. Total practice score was $78 \%$ \& classified as:

- Incompetent score of practice $<60 \%$

- Competent score of practice $\geq 60 \%$

\section{Aim of the guideline}

- This study aims to identify the effect of guideline protocol for nurses' performance regarding care provided toward poisoned preschool age children.

- The sample was divided according to their numbers into small group; each group contain (5) nurses each nurse received 10 sessions each session lasted one hour.

\section{- First phase:}

A pretest was carried out using the previous tools to assess knowledge and practice of nurses related to care of poisoned preschool age

\section{- Second phase:}

The pre-test findings were analyzed to detect the actual needs of nurses' (practice and knowledge) then, general and specific objectives of guideline protocol of child poisoning were organized in ten sessions

-The first session;

- Definition of acute poisoning, causes, types, clinical manifestation, complication, nursing care

-The second session

- Definition of petroleum poisoning, causes, clinical manifestation, complication, nursing care
- Third session

- Definition of corrosive poisoning, causes, clinical manifestation, complication, nursing care

- Fourth session

- Definition of chemical poisoning, causes, clinical manifestation, complication, nursing care

- Fifth session

- Immediate nursing care provided to poisoned children at admission

- Sixth session

- Vital signs assessment and gastric lavage procedure

- Seventh session

- Cardiopulmonary resuscitation.

- Eighth session

- Pain assessment scale and Glasgow coma scale

- Ninth session

- Skin care procedure and mouth care procedure.

- Tenth session

- ECG procedure and AVPU scale.

\section{Designing guideline protocol for nurses:}

Designing the guideline program had taken a period of time that extended from beginning of October 2019 to end of November 2019. The researcher designed bilingual guideline protocol based on the actual need assessment of the study sample.

\section{Tool validity and reliability}

Tools validity was tested through a jury of three experts of pediatric nursing. The experts reviewed the tool its clarity, relevance, comprehensiveness, simplicity and applicability. Minor modifications were done in form of question's order and the terms used in formulation of questions. This phase took a period of 
one month from the beginning to the end January 2019.

Testing reliability of proposed tools was done by the researcher through using Cronbach's alpha test.

Knowledge reliability statistics Cronbach's alpha $=0.810$

Practice reliability statistics Cronbach's alpha $=0.852$

\section{Pilot study}

A pilot study was carried out on $10 \%$ of the total sample size (5 nurses). It was to test content validity, clarity, applicability and feasibility of the study tools and to estimate the time need to fill each tool (I \&II). This phase took one month from beginning to end of February, 2020. Radical modification were done in some questions (types of poisoning and case needs for hemodialysis) and tool (II) were done in some of checklist such as (ECG steps, CPR steps to three parts, gastric lavage steps to three parts, Glasgow coma steps and pain scale steps). Participants involved in the pilot study were excluded in the study sample.

\section{Ethical consideration}

The researcher explained the aim, nature and expected outcomes of the study to the studied nurses before their participation in order to obtain their acceptance.. Participation in the study was voluntary and nurses were informed that they have the right to withdraw at any time of the study. An oral consent was taken from nurses in relation to their acceptance to participate.

\section{Field work}

The process of data collection was carried out from the beginning of March, 2020 to October 2020. The researcher interviewed nurses at the poison care center in the first floor. The aim of the study was explained to the Head of the department to get the oral approval to conduct the study. Data was collected three days weekly Sunday, Monday and Wednesday during the morning and afternoon shifts. The first phase (assessment phase) was prior to developing the educational guideline protocol in order to identify nurses' actual educational need. A posttest was conducted following providing health education about the guidelines protocol in order to evaluate the effect of protocol guideline on nurses' performance regarding care of poisoned pre-school age children.

The researcher interviewed each nurse individually and explained the aim of the study and took their approval prior to data collection. Then, the researcher assessed nurses' knowledge and observed their practice regarding poisoned children using the previous mentioned tools. The researcher observed nurses' practice during caring for poisoned pre-school age using checklist.

\section{A- Interviewing and assessment phase}

The interviewing questionnaire sheets were administered by the researcher to all nurses individually in order to collect personal data and to assess their knowledge. Explanation of the questionnaire was done. The average time required to complete each questionnaire sheet was 20-30minutes. The researcher observed nurses' actual practice during caring for poisoned preschool children checklist. This period took about two months (from beginning of January to end of February 2020) where 3-4 nurses were interviewing each time depending on their physical and mental readiness in addition to the work environment related factor. 


\section{Development of the guide line protocol}

Based on the obtained results from pretest, the guidelines protocol was designed about care of poisoned preschool age. A booklet concerning care of poisoned pre-school children was developed . Afterwards. session number and their contents, different methods of teaching and instructional media were developed.

\section{B- Implementation phase}

The implementation phase was achieved through 10 session at a period of 10 week (1-2 session / week). Each session started by summary of the previous session and objectives of the current session. Motivation and reinforcement were used during the session to encourage nurses' participation in the study. Demonstration and redemonstration were applied in order to ensure appropriate practice.

The total number of sessions were 10 and they were divided into four sessions for knowledge and 6 sessions for practice. Nurses were divided into groups and each group contained 5-6 nurses. Each nurse was supplemented with a copy of guideline protocol. The time of knowledge sessions ranged from 25 minutes while, The time of each practical session ranged from 45-60 minutes.

Different methods of teaching were used such as; discussion, lecture, brain storming, role play, demonstration and re- demonstration for each group. Media utilized were guideline guided by an educational booklet and power point which were constructed by the researcher after reviewing the related literature about the research problem and poisoned children.

\section{C- Evaluation phase}

During the evaluation phase, the the same forms of tools which were used before the implementation for all nurses. This was done immediately after the intervention and took 12 weeks( from the middle of May to middle of august 2020 )

\section{Statistical analysis:}

The collected data were organized, coded, computerized, analyzed and tabulated by electronic computer and Statistical Package for Social Sciences (SPSS) version 20. The collected were represented in term of number, percentage distribution, mean, standard deviation, relation co efficient Chi- quare test and correlation. A statistical significant difference was considered if $\mathrm{P} \leq .05$. A highly statistical significant difference if $\mathrm{P} \leq . .01$

\section{Results:}

Table (1): Illustrates that $40 \%$ of the studied nurses were 20 - years old with mean age 28.59 years. Moreover, $80 \%$ were females. It was found also that $54 \%$ of nurses had completed their education in nursing secondary school.

Table (2):- Reflects that, slightly less than half $(46 \%)$ of children had poisoning from medication. Meanwhile, less than half (44\%) of children had loss of conscious level

Table (3): Total mean score of the studied nurses' knowledge about poisoning, there was highly statistically significance difference between total knowledge score of nurses pre and post tests regarding poisoning, petroleum, medication, corrosive and role of nurse for mother about chemical poisoning $\mathrm{P}$ (0.000). A highly statistical significant difference was found between levels of knowledge on pre and post tests $(\mathrm{P}<$ 0.001 
Figure (1): represents that, $66 \%$ of studied nurses had poor knowledge score regarding poisoning on pretest compared to $80 \%$ of nurses who had good knowledge score on post test $(\mathrm{p}>0.01)$.

Table (4): reveals that there was a highly statistical significance difference between total practice score of nurses pre and post guideline regarding vital signs assessment and clinical examination, conscious level (AVPU), glasgow coma scale, immediate nursing care provided at admission for poisoned children, cardiopulmonary resuscitation procedure, mouth care, skin care, electrical cardiograph, Face Pain Scale and gastric catheter lavage procedures $\mathrm{P}(0.000)$.

This figure (2): represents that $78 \%$ of the studied nurses had poor practice score regarding poisoning at pre guideline compared to $92 \%$ of nurses who had good practice score at post test ( $\mathrm{p}>0.01)$.

Table (5): shows that there was a positive correlation between total nurse' knowledge and total practice score regarding children nursing procedures in pre and post tests $(\mathrm{p}<0.01)$.

Table (1):- Characteristics of studied nurses

\begin{tabular}{|c|c|c|}
\hline \multirow{2}{*}{ Items } & \multicolumn{2}{|c|}{ Nurses $(n=50)$} \\
\hline & No & $\%$ \\
\hline Age & & \\
\hline$\leq 20$ year & 4 & 8.0 \\
\hline $20-$ & 20 & 40.0 \\
\hline $25-$ & 12 & 24.0 \\
\hline$\geq 35$ years & 14 & 28.0 \\
\hline $\mathrm{X} \pm \mathrm{SD}$ & $28.59 \pm 4.56$ & \\
\hline Gender & & \\
\hline Male & 10 & 20.0 \\
\hline Female & 40 & 80.0 \\
\hline Educational qualification & & \\
\hline Diploma of nursing & 27 & 54 \\
\hline Technical nursing & 14 & 28 \\
\hline Bachelor degree & 9 & 18.0 \\
\hline Job description & & \\
\hline Nurse & 42 & 84.0 \\
\hline Head of department & 4 & 8.0 \\
\hline Unit supervisor & 4 & 8.0 \\
\hline Years of experiences & & \\
\hline Less $<1$ year & 14 & 28.0 \\
\hline $1-$ & 14 & 28.0 \\
\hline $3 \leq 6$ years & 6 & 12.0 \\
\hline More than 6 years & 16 & 32.0 \\
\hline $\mathbf{X} \pm$ SD & & \\
\hline Marital status & & \\
\hline Single & 12 & 24.0 \\
\hline Widow & 0 & 0.0 \\
\hline Divorced & 0 & 0.0 \\
\hline Married & 38 & 76.0 \\
\hline
\end{tabular}


Effect of Guidelines Protocol for Nurses' Performance Regarding Care Provided toward Poisoned Pre-school Age Children

Table (2): Number and percentage distribution of the studied children regarding their medical characteristics

\begin{tabular}{||l|c|c||}
\hline \multicolumn{1}{|c|}{ Items } & \multicolumn{2}{c||}{ Children ( $\mathrm{n}=100)$} \\
\cline { 2 - 3 } & $\mathrm{No}$ & $\%$ \\
\hline $\begin{array}{l}\text { Type of poisoning } \\
\text { Dietary }\end{array}$ & 2 & 2.0 \\
\hline Corrosive & 32 & 32.0 \\
\hline Medication & 46 & $\mathbf{4 6 . 0}$ \\
\hline Petroleum & 20 & 20.0 \\
\hline $\begin{array}{l}\text { Signs and symptoms came in center } \\
\text { Vomiting }\end{array}$ & 40 & 40.0 \\
\hline Loss of consciousness & 44 & 44.0 \\
\hline Difficult breathing & 16 & 16.0 \\
\hline $\begin{array}{l}\text { Child exposure poisoned before } \\
\text { Yes }\end{array}$ & 32 & 32.0 \\
\hline No & 68 & $\mathbf{6 8 . 0}$ \\
\hline $\begin{array}{l}\text { Risk time of poisoning } \\
8 \text { am }-4 \text { pm }\end{array}$ & 34 & $\mathbf{3 4 . 0}$ \\
\hline 4 pm - 12 am & 26 & 26.0 \\
\hline 12 am - 8 am & 12 & 12.0 \\
\hline Other (any time) & 28 & 28.0 \\
\hline \hline
\end{tabular}

Table (2):- Total mean score of the studied nurses' knowledge types of regarding poisoning at pre/ post guideline.

\begin{tabular}{|c|c|c|c|c|}
\hline \multirow{3}{*}{ Items } & \multicolumn{2}{|c|}{ Nurses $(n=50)$} & \multirow{3}{*}{ t-test } & \multirow{3}{*}{$P$ value } \\
\hline & $\begin{array}{c}\text { Pre } \\
\text { guideline }\end{array}$ & $\begin{array}{c}\text { Post- } \\
\text { guideline }\end{array}$ & & \\
\hline & $\mathrm{X} \pm \mathrm{SD}$ & $\mathrm{X} \pm \mathrm{SD}$ & & \\
\hline Poisoning & $14.42 \pm 2.54$ & $21.92 \pm 1.67$ & 40.01 & $0.000 * *$ \\
\hline Petroleum poisoning & $5.1201 .28 \pm$ & $9.24 \pm 1.18$ & 28.11 & $0.000 * *$ \\
\hline Medication poisoning & $5.68 \pm 0.93$ & $9.26 \pm 1.08$ & 42.93 & $0.000 * *$ \\
\hline Corrosive poisoning & $5.80 \pm 1.24$ & $9.52 \pm 0.83$ & 32.93 & $0.000 * *$ \\
\hline $\begin{array}{l}\text { Role of nurse for mothers about } \\
\text { chemical poisoning }\end{array}$ & $3.56 \pm 3.39$ & $9.28 \pm 1.35$ & 7.41 & $0.000 * *$ \\
\hline Total & & & 41.98 & $0.000 * *$ \\
\hline
\end{tabular}




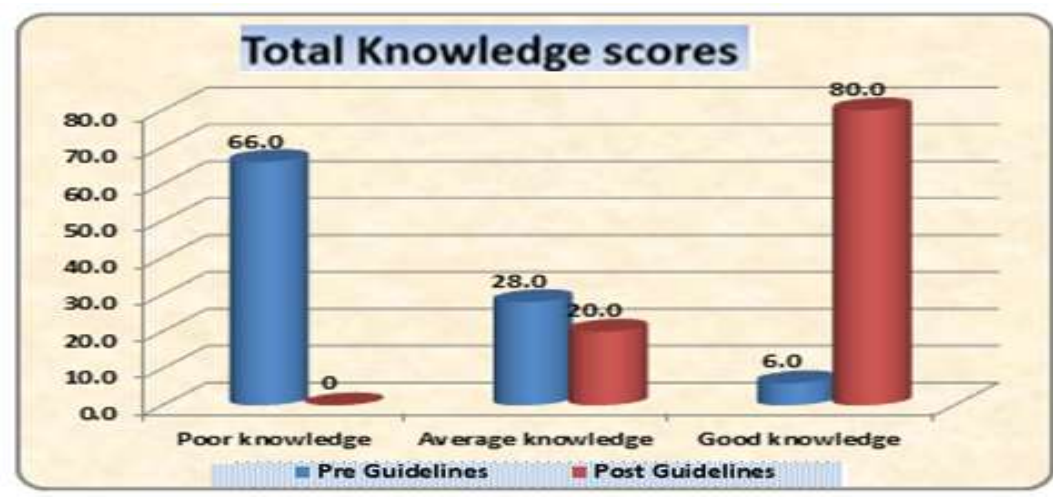

Figure (1): Total score of the studied nurses' knowledge regarding poisoning at pre and post guideline, $(n=50)$

Table (4): Total mean score of the studied nurses' practice on pre- post tests

\begin{tabular}{|c|c|c|c|c|}
\hline \multirow{3}{*}{ Items } & \multicolumn{2}{|c|}{ Nurses $(n=50)$} & \multirow{3}{*}{ t-test } & \multirow{3}{*}{$P$ value } \\
\hline & \multicolumn{2}{|c|}{ Total nurses' practice } & & \\
\hline & $\mathrm{X} \pm \mathrm{SD}$ & $\mathrm{X} \pm \mathrm{SD}$ & & \\
\hline $\begin{array}{l}\text { 1- Vital signs assessment and } \\
\text { clinical examination }\end{array}$ & $5.66 \pm 1.13$ & $10.40 \pm 1.47$ & 35.23 & $0.000 * *$ \\
\hline 2- Conscious level (AVPU) & $0.44 \pm 0.50$ & $\begin{array}{l}0.80 \pm \\
0.040\end{array}$ & 6.20 & $0.000 * *$ \\
\hline 3-Glasgow coma scale & $0.80 \pm 1.10$ & $2.58 \pm 0,67$ & 5.11 & $0.000 * *$ \\
\hline $\begin{array}{l}\text { 4-Immediate nursing care } \\
\text { provided at admission for } \\
\text { poisoned children }\end{array}$ & $8.12 \pm 1.23$ & $13.00 \pm 1.37$ & 46.32 & $\mathbf{0 . 0 0 0} * *$ \\
\hline $\begin{array}{l}\text { 5-Cardiopulmonary } \\
\text { resuscitation procedure }\end{array}$ & $12.72 \pm 2.11$ & $21.34 \pm 3.12$ & 42.44 & $0.000 * *$ \\
\hline 6-Mouth care procedure & $4.16 \pm 1.36$ & $7.68 \pm 0.91$ & 21.61 & $0.000 * *$ \\
\hline 7-Skin care procedure & $4.24 \pm 1.61$ & $8.54 \pm 1.11$ & 18.61 & $0.000 * *$ \\
\hline $\begin{array}{ll}\text { 8-Electrical } & \text { cardiograph } \\
\text { procedure } & \\
\end{array}$ & $7.42 \pm 1.52$ & $11.40 \pm 1.62$ & 34.37 & $0.000 * *$ \\
\hline 9-Face Pain Scale & $0.00 \pm 0.00$ & $0,84 \pm 0.37$ & 16.03 & $0.000 * *$ \\
\hline 10-Gastric catheter lavage & $9.80 \pm 2.69$ & $18.48 \pm 2.34$ & 25.70 & $0.000 * *$ \\
\hline
\end{tabular}


Effect of Guidelines Protocol for Nurses' Performance Regarding Care Provided toward

Poisoned Pre-school Age Children

Table (5): Correlation coefficient between total knowledge score and total practice score of the studied nurses in pre and post guideline

\begin{tabular}{|c|c|c|c|c|c|c|c|c|}
\hline \multirow[t]{3}{*}{ Variables } & \multicolumn{8}{|c|}{ Total knowledge score } \\
\hline & \multicolumn{4}{|c|}{ Pre test $(n=50)$} & \multicolumn{4}{|c|}{ Post test $(n=50)$} \\
\hline & $\mathbf{R}$ & $\mathbf{P}$ & $\mathbf{r}$ & $\mathbf{P}$ & $\mathbf{R}$ & $\mathbf{P}$ & $\mathbf{r}$ & $\mathbf{p}$ \\
\hline Total practice score & 0.157 & 0.276 & 0.33 & 0,818 & 0.189 & 0.188 & 0.963 & $\begin{array}{c}0.00 \\
* *\end{array}$ \\
\hline
\end{tabular}

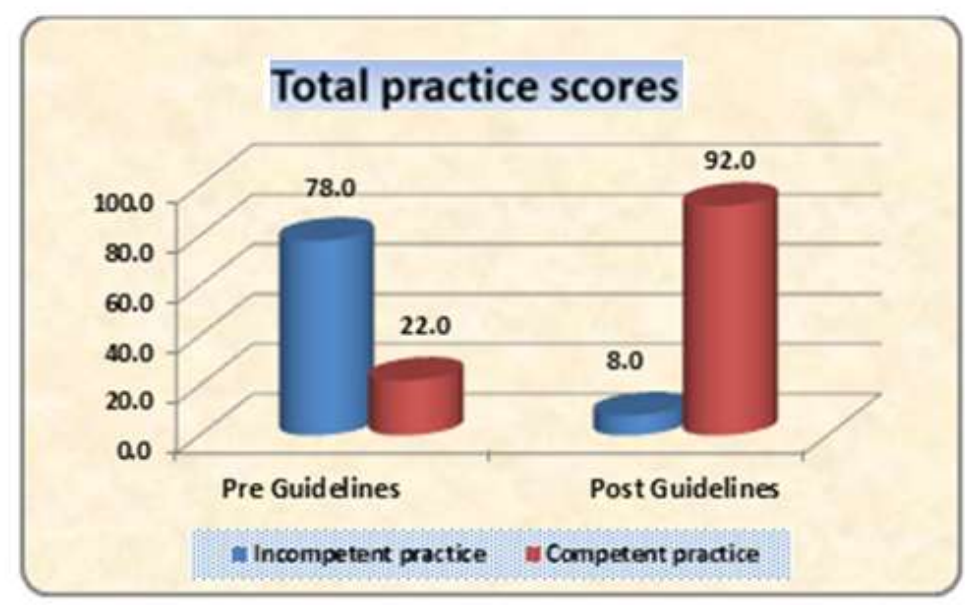

Fig ( 2 ):Total score of the studied nurses' practice

\section{Discussion}

Poisoning is a common medico-social problem all over the world which may result in morbidity and mortality of children. Acute poisoning is a common medical emergency in pediatric unit. Poisoning is usually common during the summer season. Poisoning is a common problem among preschool age children because they are very active to explore the world around them. Their curiosity goes anywhere and everything goes into the mouth (Abbas et al., 2014).

The present study was a quesi experimental study included a convenient sample of $50 \mathrm{u}$ from Benha university hospital. Worked at poisoned center to assess effect of guideline protocol for nurses' performance regarding care provided toward poisoned preschool age children.

Regarding personal characteristics of the studied nurses, the results of the present study revealed that, less than half of the studied nurses, were between $20<25$ years with mean age 28.59. This result was similar to the results of a study by Abdellah, (2018) who conducted a study to " Assessment of nurses' knowledge regarding initial management poisoning among children under five years in Alamal National Hospital , who found that, the age group of nurses were between 20>29years

Concerning qualification level of the studied nurses, the present study viewed that, more than half of the studied nurses had diploma of nursing (secondary school), This finding 
disagree with, Abebe et al., (2019) in a study about "Assessment of knowledge and practice of nurses of initial management of acute poisoning in Dessie referral hospital Amhara region 2018 Assessment of knowledge and practice of nurses of initial management of acute poisoning in Dessie referral hospital Amhara region 2018", who reported that, more than half of nurses had bachelor degree.

The present study revealed that, more the third than of the studied child had vomiting. This result in accordance with Bairaq \& Faiahat (2011) in a study entitled " Pattern and determinants of poisoning in a teaching hospital in Riyadh, Saudi Arabia ", who demonstrated that, the majority of the studied children had vomiting.

The present study revealed that, less than half of the studied child were exposed to different types of poisoning, which may be due to parent don't have knowledge about storage of medication. This result in accordance with Marriott, et al. (2013) in a study entitled " Unintentional ingestion of over the counter medications in children less than 5 years old ", who demonstrated that, the majority of the child studied had medication poisoning.

The finding of the current study highlighted that, more than two third of studied nurses had poor score of knowledge at pre guideline phase, this could be due to the fact that this course not included in the curriculum of nursing, the majority of nurses didn't attend any training program related poisoning in pre-school, the lack of nurses' incentives and desire to enhance or at least refresh their knowledge whether new and old graduated nurses as well as the work load and keeping nurses away from updating knowledge and lack of continuous training program.. On the other hand, the majority of the studied nurses had good knowledge level post-guideline protocol. This could be attributed to the guideline content which was developed based on nurses' needs regarding care of poisoned children. The positive change in the total score of nurses' knowledge indicates that the guideline was effective in improving nurses' knowledge in relation to poisoned pre-school age children.

Concerning total score of practice of the studied nurses regarding nursing care providing to poisoned children, the present study revealed that, the most of the studied nurses had an incompetent score. This might be due to lack of continuous training and education performed for the nurses regarding care providing to poisoned children in addition, the head of department limited some procedure only doctor or charged nurse perform it like gastric lavage.

The finding of the current study is compatible with Ruto et al., (2012) who carried out study to assess Nurse's knowledge, attitude and practice on the initial management of acute poisoning among children casualties: Study at Kenyatta National Hospital, Kenya and showed that the most of nurses had poor level of performance regarding management of acute poisoning among children practices. Following the implementation of guideline, the majority of the studied nurses had a competent score in the post - guideline phase and there is highly statistical significant difference in nurses' practice score post- guideline as compared to the pre- guideline $(\mathrm{p}<0.00)$. This might be because refreshment in nurses' knowledge which in turn led to an improvement their 
practice nurses regarding care providing to poisoned children.

\section{Conclusion}

There was a highly statically significant improvement in the studied nurses' knowledge and practice score regarding poisoned preschool age guideline protocol intervention when compared with pre guideline protocol intervention.

\section{Recommendations}

1-Provision of continuing education programs should be provided in order to update nurses knowledge and enhance their competency level regarding in the care of poisoned pre - school children.

2-Designing and distributing Arabic booklets should be designed to all nurses who are working in poisoning units including all knowledge and practice related poisoned children.

3-Periodic evaluation of nurses' performance level by hospital directors to detect the points of strength and weakness to act on.

4-Further researches, the study should be replicated on a larger random sample in different setting for the generalization of the obtained results.

5-Adding the poisoning course to curriculum of nursing

\section{References}

Abdallah, D. (2018). who conducted a study about assessment of nurses knowledge regarding initial management of poisoning among children under 5 years in Alamal, master thesis, shani university, 170-171.

Abbas, S., Tikmani, S. \& Siddiqui, A. (2014). Accidential Poisoning Children, Journal of the Pakistan Medical Assosciation, 62(4):44-51
Abebe, A . Kaswa, M. \& Shewanashaw, N. (2019). Assessment of knowledge and practice of nurses on initial management of acute poisoning in Dessie referral hospital Amhara region, Ethiopia, 2018, BMC Nursing, 16(60): 1-8.

Alanazi, M. Al-jeriasy, M. Al- Assiri, M. \& Allhammad, L. (2015). Risk factor of acute poisoning among children, A study at poisoning unit of university hospital in Egypt r, Med,gov J, 10(1097): 23-39.

Anant, J. Inchulkar, S., D . Bhagat, S. (2018). A review on Gasteric Lavage in the management of Ingestion Poisoning, Europian Journal of Pharmacological and Medical research,5(10), 167-171

Bairaq, A \& Faiahat, F. (2011). Pattern and determinants of poisoning in a teaching hospital in Riyadh, Saudi Arabia, Elseriei J,19(1): 53-63.

Hassan, B . \& Mohamed, G. (2020). Patterns of Acute Poisoning in Childhood in Zagazig, Egypt: An Epidemiological Study, Zigzag medical journal, 5(27): 245-279.

Marriott, J. Ashby, K. \& Smith, J. (2013). Unintentional ingestion of over the counter medications in children less than 5 years old,Journal of Paediatrics and Child Health 39(4):264-269.

Nickson, C. (2017). Gasteric lavage in pediatric, Home/Critical compendium Journal, 4(6):102-113

Nixon, J. Spinks, A. Turner, C. Clure, R.(2014). Community based programs to prevent poisoning in children $0-15$ years. Inj Prev. ;10:43-6

Rutto, J., Mwaura, J., Chepchirchir, A., \& Odero, T. (2012). Nurse's knowledge, attitude and practice on the initial 
management of acute poisoning Effect of Designed Nursing, Open Journal of Nursing, 02(03):149-156

Saikia, D. Sharma, R. \& Janardhan, K. (2020). Clinical profile of poisoning due to various poisons in children of age $0-12$ years, J Family Med Prim Care, 9(5):291-296

Seif, E. Goma, R., \& Eisa, M.(2017). A Respective Study of acute Poisoning in Children under 5 Years Old Admitted To Alexanderia Poison Center in Egypt, Journal of Medical, 4(2):32-39.

Shablaby, S., Azab, S., Rafie, N \& Tawifik, H. (2015). Epidemiological Study of Acute
Toxicity in Children Admitted to Poison Control Center, Ain Shams University Hospitals during the Year 2012 -A Retrospective Study, Ain Shams journal, 19(4): 31-43.

Vilaca, L. Volpe, F. \& Ladeira, R. (2019). Accidental Poisoning in Children and Adolenscence Admitted to A referral Toxicology Department of A barizalian Emergency Hospital, paul Pediatr journal, ISSN 1984-0462,1-11. 
تأثير البرتوكول التوجيهى لأداء الممرضات تجاه الرعايه التمريضيه المقدمه لتسمم الأطفال ما قبل السن المدرسى الجرعايه نوره عبدالفتاح محمود ـ أمل محم الاخاخنى - باسمه ربيع عبدالصادقـ- أمل عبدالعزيز عبدالسلام

تقوم الممرضه بدور هام في تقديم الرعايه اللازمه للاطفال المسمون. لذلك هدفت الدراسه الي تقييم معلومات

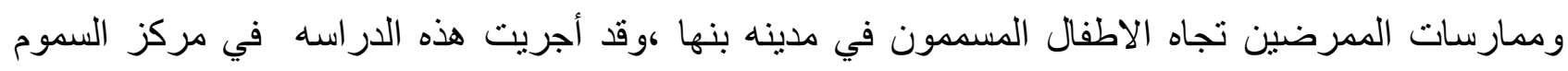

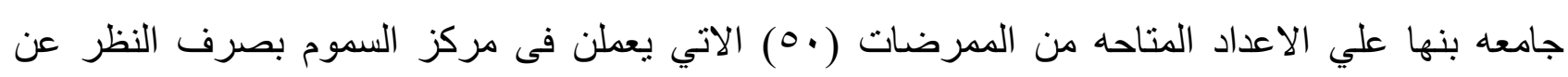

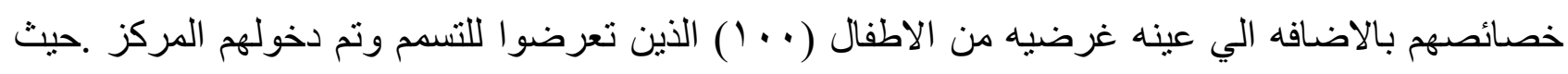

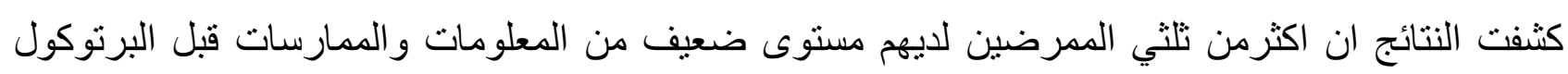

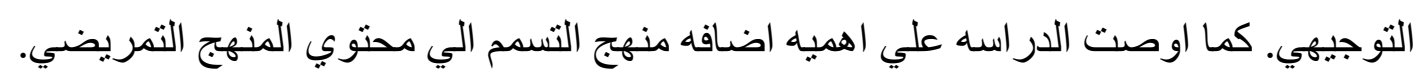

